\title{
Indications for fusion following decompression for lumbar spinal stenosis
}

\section{Mark W. Fox, M.D., and Burton M. Onofrio, M.D.}

Neurosurgery Associates, Limited, St. Paul, Minnesota; and Department of Neurosurgery, The Mayo Clinic, Rochester, Minnesota

Degenerative lumbar spinal stenosis is a common condition affecting middle-aged and elderly people. Significant controversy exists concerning the appropriate indications for fusion following decompressive surgery. The purpose of this report is to compare the clinical outcomes of patients who were and were not treated with fusion following decompressive laminectomy for spinal stenosis and to identify whether fusion was beneficial. The authors conclude that patients in whom concomitant fusion procedures were performed fared better than patients who were treated by means of decompression alone when evidence of radiological instability existed preoperatively.

\section{Key Words * lumbar spinal stenosis * laminectomy * fusion * indication}

The decision to perform fusion following decompression for degenerative lumbar spinal stenosis has been studied by many authors.[14,16,30,52,69] Unfortunately, no clear consensus has been reached to determine which patients are most likely to benefit from a concomitant lumbar fusion. Patient satisfaction following lumbar decompression alone ranges from 59 to $96 \%$, with early surgical failures resulting from inadequate decompression and preoperative lumbar instability.[2,4,8,12,21,22,26,29,31,34,65] Late recurrence of back or leg problems may also result from acquired spinal instability.

The goal of this study was to analyze clinical outcomes in patients treated with and without fusion following lumbar decompression to determine which patients benefited most. The ability to identify predictive factors for successful surgery with fusion would improve overall clinical results and decrease both early and late failures caused by persistent or acquired spinal instability.

\section{CLINICAL MATERIAL AND METHODS}

Between January 1, 1986, and June 30, 1988, 178 consecutive patients at the Mayo Clinic underwent decompressive lumbar laminectomy for degenerative lumbar stenosis and form the basis for this study. This retrospective work has been previously reported by Fox, et al.[16] One hundred twenty-four patients (70\%) participated in this study, which required completion of a detailed questionnaire and standing anteroposterior, lateral, and flexion-extension lumbar spine radiographs. 
All medical and surgical records including pre- and postoperative radiographs were reviewed. Questionnaires completed by patients compared their preoperative and postoperative symptoms, including their abilities to walk and perform common daily activities. In addition, the presence or absence of back and leg pain, numbness, and weakness before and after surgery were addressed. All radiographs were reviewed specifically for the preoperative presence or development of spondylolisthesis after surgical decompression. Patient-reported outcomes were then correlated with investigator-determined evidence for postoperative radiological spinal instability.

\section{Patient Characteristics}

There were 65 men and 59 women with an average age of 67.5 years (range $34-83$ years). The mean follow-up period was 5.8 years (range 4.6-6.8 years). Preoperative back pain was present in $87 \%$ of patients whereas leg pain(s) was present in $94 \%$. Pseudoclaudication was reported by $83 \%$ of patients.

\section{Radiological Characteristics}

Table 1 summarizes the preoperative level, direction, and magnitude of subluxation in the patients studied. Notably, 60 patients (48\%) had anterior subluxation of $3 \mathrm{~mm}$ or more, 23 (19\%) had retrospondylolisthesis, and $42(34 \%)$ had some degree of lateral spondylolisthesis. Pre- and postoperative disc heights, lateral lumbar curvatures, facet angles, anterior osteophytes or traction spurs, and relative sagittal angulation measurements were also recorded.

\begin{tabular}{|c|c|c|c|c|c|}
\hline \multicolumn{6}{|c|}{$\begin{array}{c}\text { TABLE } 1 \\
\text { PREOPERATME LEYEL, DIRECTION, AND MAGN TUDE OF SUELUXATION IN } 124 \\
\text { PATIENTS WITH LUMEAR SPINAL STENOSIS }\end{array}$} \\
\hline \multirow[b]{2}{*}{ Subluxation (mm) } & \multicolumn{5}{|c|}{ No. of Affected Levels } \\
\hline & $\overline{\mathrm{L} 1-2}$ & $L 2-3$ & $L 3-4$ & L4-5 & $\overline{L 5-S 1}$ \\
\hline \multicolumn{6}{|l|}{ anterior } \\
\hline $3-5$ & 1 & 0 & 9 & 21 & 3 \\
\hline $6-10$ & 0 & 0 & 2 & 23 & 2 \\
\hline $11-15$ & 0 & 0 & $\overline{0}$ & 6 & $\overline{0}$ \\
\hline$>16$ & 0 & 0 & 0 & 1 & 1 \\
\hline \multicolumn{6}{|l|}{ posterior } \\
\hline & 0 & 4 & 10 & 7 & 5 \\
\hline $6-10$ & 0 & 0 & 0 & 1 & 0 \\
\hline $11-15$ & 0 & 0 & 0 & 0 & 0 \\
\hline$>16$ & 0 & 0 & 0 & 0 & 0 \\
\hline \multicolumn{6}{|l|}{ lateral } \\
\hline $3-5$ & 0 & 2 & 15 & 30 & 4 \\
\hline $6-10$ & 0 & 2 & 4 & 1 & 0 \\
\hline $11-15$ & 0 & $\overline{0}$ & 0 & 0 & 0 \\
\hline$>16$ & 0 & 0 & 0 & 0 & 0 \\
\hline
\end{tabular}

All 124 patients underwent postmyelographic computerized tomography (CT) scanning and all had anteroposterior canal diameters measuring $12 \mathrm{~mm}$ or less. In addition, there were 14 patients with disc herniations located on the same side as their preoperative leg pain that were deemed significant enough to remove at surgery.

\section{Surgical Characteristics}

Ninety-two patients (74\%) underwent lumbar decompression alone, and 32 patients (26\%) underwent 
concomitant posterolateral fusion. The fusions were performed with autogenous iliac crest bone graft alone (15 patients) or with the adjunctive use of Isola instrumentation (17 patients)(Acromed Corp., Cleveland, $\mathrm{OH}$ ). Fusions were performed at one level in 18 patients, two levels in seven patients, and three levels in six patients; one four-level fusion was performed. The most common level fused was L4-5 in 29 of 32 patients, followed by L5-S1 in 14 patients, L3-4 in seven patients, and L2-3 in two patients. All patients wore a custom-fitted lumbosacral spinal orthosis for 3 months following surgery.

The decision to fuse was based on several factors. The most common reason was significant preoperative low-back pain associated with preoperative spondylolisthesis and dynamic instability observed on flexion-extension radiographs in 18 patients. Fusion was performed in an additional 10 patients who required an extensive decompression across a minimally degenerated L4-5 disc space. Following aggressive canal decompression via bilateral inferior facetectomies, medial superior facetectomies, and bilateral foraminotomies, the spines in four patients were intraoperatively determined to be unstable and underwent concomitant fusions.

\section{RESULTS}

\section{Patient-Reported Outcomes}

Fifty-eight (47\%) of 124 patients reported no back pain at follow up, whereas 46 patients (37\%) were improved. Only seven patients $(6 \%)$ reported worsened back pain. Seventy-five patients $(60 \%)$ reported no leg pain and $26(21 \%)$ reported improved leg pain, whereas six $(5 \%)$ reported worse pain. Eighty-eight (71\%) reported improved walking ability, whereas $107(86 \%)$ claimed little or no need for help with their usual activities of daily living.

\section{Overall Outcome in Patients With and Without Fusion}

There was a reduced incidence of poor outcomes among those patients who underwent fusion. Ninety-one percent of those who underwent concomitant fusion procedures had good or fair outcomes compared with only $75 \%$ of those who underwent decompression alone. Table 2 summarizes patient-reported outcomes based on preoperative anterior subluxation, whether fusion was performed and what type, and whether postoperative progression of anterior subluxation had occurred.

\begin{tabular}{|c|c|c|c|c|c|}
\hline Summs & OF PATIENT-RE PORT LUM & $\begin{array}{l}\text { TABLE } 2 \\
\text { OUTCOMES FOLLO } \\
\text { SPINAL STENOSIS }\end{array}$ & DECOM & ION F & \\
\hline \multirow{2}{*}{$\begin{array}{c}\text { Occurrence of } \\
\text { Preop Sip } \\
\text { (no. of patients) }\end{array}$} & \multirow{2}{*}{$\begin{array}{c}\text { Type of } \\
\text { Fusion } \\
\text { [no. of patients] }\end{array}$} & \multirow{2}{*}{$\begin{array}{c}\text { Postop Slip } \\
\text { (no. of patients) }\end{array}$} & \multicolumn{3}{|c|}{ Outcome } \\
\hline & & & Good & Fair & Poor \\
\hline \multirow[t]{6}{*}{ no preop slip (64) } & none (62) & increased (20) & 7 & 8 & 5 \\
\hline & & no change (42) & 22 & 5 & 15 \\
\hline & lat mass only (1) & increased (0) & 0 & 0 & 0 \\
\hline & & no change (1) & 1 & 0 & 0 \\
\hline & Steffese plate (1) & increased (0) & 0 & 0 & 0 \\
\hline & & no change (1) & 0 & 1 & 0 \\
\hline \multirow{6}{*}{ preop slip (60) } & none (30) & increased (22) & 12 & 7 & 3 \\
\hline & & no change (8) & 3 & 4 & 1 \\
\hline & lat mass only (15) & increased (8) & 3 & 5 & 0 \\
\hline & & no change (7) & 4 & 2 & 1 \\
\hline & Steffee plate (15) & increased (2) & 1 & 0 & 1 \\
\hline & & no change (13) & 7 & 6 & 0 \\
\hline
\end{tabular}

* See Results section for description of outoomes. 
Patient outcome was graded as good if patients had no back or leg pain, unlimited walking ability, and the ability to perform daily activities unassisted; fair, if outcome improved back and/or leg pain but with some modification of performance of daily activities; and poor, if outcome was no improvement or worsening of preoperative symptoms, increased difficulty in walking and ability to perform daily activities, or continued, severe postoperative back pain. In this study, when all patients were considered postoperatively, 60 patients (48\%) achieved good results, 38 patients (31\%) experienced fair results, and 26 patients $(21 \%)$ had poor results.

Comparison of the 26 poor-outcome patients with the other 98 good- and fair-outcome patients revealed no significant differences with respect to age, weight, height, preoperative back or leg symptoms, preoperative bladder or bowel function, preoperative walking ability, or performance of daily activities. The 26 patients with a poor outcome were slightly more likely to be male (16 men vs. 10 women) and to have preoperative retrospondylolisthesis (27\% of those with preoperative retrospondylolisthesis experienced poor outcomes compared with only $2 \%$ of those without).

\section{Incidence of Postoperative Subluxation}

Anterior Subluxation. Anterior spondylolisthesis was present at 69 levels in 60 patients prior to surgery (Table 1). Progressive postoperative subluxation occurred in 32 of these patients. The mean vertebral slippage was $5.1 \mathrm{~mm}$ (range 2-13 $\mathrm{mm}$ ). Twenty of 64 patients without preoperative anterior subluxation developed anterior slippage postoperatively (mean $7.8 \mathrm{~mm}$, range $2-20 \mathrm{~mm}$ ). For those with preoperative slippage, the incidence of further postoperative subluxation was one of one at L1-2, 10 of 11 at L3-4, 40 of 51 at L4-5, and one of six at L5-S1. Table 3 correlates the magnitude of preoperative anterior spondylolisthesis with the incidence of postoperative progression at L4-5, the most common site for progressive subluxation.

\begin{tabular}{|c|c|c|}
\hline \multicolumn{2}{|c|}{\begin{tabular}{|l} 
TABLE 3 \\
\end{tabular}} & ND THE INCIDENCE OF \\
\hline \multirow{2}{*}{$\begin{array}{l}\text { Preop Degee } \\
\text { of } L 4-5 \text { Sip (mrn) }\end{array}$} & \multicolumn{2}{|c|}{ Postop Slip } \\
\hline & Wo Fusion (\%) & Fusion (\%) \\
\hline $\begin{array}{l}0-2 \text { (73 patients) } \\
3-5 \text { (21 patients) } \\
6-10 \text { (23 patients) } \\
11-15 \text { (6 patients) } \\
\text { >16 (1 patient) } \\
\text { total }\end{array}$ & $\begin{array}{c}14 \text { of } 71(19.7) \\
10 \text { of } 16(62.5) \\
4 \text { of } 6(66.7) \\
2 \text { of } 2(100) \\
0 \\
30 \text { of } 95(31.6)\end{array}$ & $\begin{array}{c}0 \text { of } 2(0) \\
2 \text { of } 5(40) \\
7 \text { of } 17(41.2) \\
1 \text { of } 4(25) \\
0 \text { of } 1(0) \\
10 \text { of } 29(34.5)\end{array}$ \\
\hline
\end{tabular}

Posterior Subluxation. Table 1 summarizes the incidence and level of preoperative posterior spondylolisthesis. It was most common at the L3-4 and L4-5 levels (10 and eight patients each, respectively) and less common at the L2-3 and L5-S1 levels (four and five patients each, respectively). The incidence of progressive postoperative posterior subluxation was one of four at L2-3, three of 10 at L3-4, zero of eight at L45, and one of five at L5-S1. None of these patients underwent fusion. Of patients without preoperative retrospondylolisthesis, none developed it following decompressive surgery.

Lateral Subluxation. Seven (9\%) of 82 patients without preoperative side-to-side or lateral subluxation developed lateral slippage following decompressive surgery, whereas six (14\%) of 42 patients with 
preoperative lateral slippage progressed at eight levels. The most common sites were the L4-5 and L3-4 (four and three patients, respectively), although the degree of preoperative slippage did not correlate with the risk for progression.

\section{Lateral Lumbar Curvature and the Incidence of Progressive Anterior Subluxation}

As the degree of preoperative lateral lumbar curvature increased, so did the patients risk for progression following decompression. However, only at lumbar curvatures greater than $21^{\circ}$ did this become significant. The risk for postoperative anterior spondylolisthesis was less for those patients with preoperative lateral lumbar curvature than for those with normal curvatures.

\section{Preoperative Disc Height and the Incidence of Progressive Anterior Subluxation}

Data collected suggest that a normal or near-normal disc height at L-4 may predispose to an increased risk for postoperative subluxation when decompression spans this disc space. Conversely, a markedly narrowed disc height at L-3 predisposed to an increased incidence for subluxation at L3-4 following decompression across the L-3 disc space.

\section{Preoperative Facet Angles and the Incidence of Progressive Anterior Subluxation}

Facet angles were measured at L3-4 and L4-5 where postoperative subluxation most commonly occurred. Only the 23 patients who underwent laminectomy alone without violation of the facet joints and did not undergo fusion were analyzed. A review of facet angles for those in whom there was no slippage postoperatively at L3-4 revealed no significant difference in facet angle when compared with those who did. However, at L4-5, those in whom slippage occurred had a mean preoperative facet angle of $65.8^{\circ}$ (nine patients), compared with a mean facet angle of $50.4^{\circ}$ (14 patients) for those in whom there was no slippage at L4-5 postoperatively. These data suggest that more sagittally oriented facet joints at L4-5 may predispose to postoperative subluxation following decompression.

\section{Radiological Comparison of Good-to-Fair Outcomes With Poor Outcomes}

Comparison of preoperative radiographic imaging revealed no differences between these groups with respect to disc heights, facet angles, or scoliosis. The number of levels decompressed and the extent of bone removal did not influence outcome. Notably, the presence of preoperative anterior spondylolisthesis or lateral vertebral slippage did not influence outcome. Futhermore, increased postoperative anterior subluxation did not influence outcome: $45 \%$ of patients with good or fair outcomes had increased postoperative subluxation compared with $35 \%$ of those experiencing a poor outcome.

Current radiographic analysis of the 26 poor-outcome patients included standing flexion-extension lumbar radiographs and either CT myelography or magnetic resonance imaging. Seventeen patients had no change in their preoperative alignment. Two patients with fusions had pseudarthroses, and of the 15 without fusion, one patient was found to have had an inadequate surgical decompression, and arachnoiditis was found in two patients. Nine patients, one of whom underwent fusion, had increased postoperative subluxation.

\section{Number of Levels Decompressed and Progressive Anterior Slippage}

Patients undergoing a one-level decompression had a $13 \%$ chance of progressive anterior subluxation following surgery. This compares to a fourfold increase in patients undergoing a two- or three-level decompression (53\% and 59\%, respectively). There were too few patients to evaluate four- and five-level 
decompressions.

\section{Extent of Decompression and Progressive Anterior Subluxation}

The extent of bone decompression determined the incidence of postoperative progression of anterior spondylolisthesis. Patients with no preoperative slippage underwent more extensive bone decompression and had a higher incidence of postoperative progressive subluxation. Patients with preoperative slippage had a significantly greater chance of progressive subluxation when compared with those in whom there was no preoperative slippage. These findings are summarized in Table 4.

\begin{tabular}{|c|c|c|c|c|}
\hline \multicolumn{5}{|c|}{$\begin{array}{c}\text { TABLE } 4 \\
\text { EXTENT OF DECOMPRESSION CORRELATED WITH THE INCIDENCE OF } \\
\text { PROGRESSIVE ANTERIOR SUBLUXATON FOLLOWING LUMBAR DECOMPRESSION } \\
\text { FOR SPINAL STENOSIS (PATIENTS WITH FUSIONS EXCLUDED) }\end{array}$} \\
\hline & \multicolumn{4}{|c|}{ Type of Sugery } \\
\hline & $\begin{array}{l}\text { Lami- } \\
\text { nestomy }\end{array}$ & $\begin{array}{l}\text { Laminectomy } \\
\text { Bilat Wedial } \\
\text { Factectomy }\end{array}$ & $\begin{array}{l}\text { Laminectomy } \\
\text { Unilat Total } \\
\text { Factectomy }\end{array}$ & $\begin{array}{l}\text { Laminectomy } \\
\text { Bilat Total } \\
\text { Fackectomy }\end{array}$ \\
\hline $\begin{array}{l}\text { no. of patients } \\
\text { wh preop anterior sip } \\
\text { increased slip }(\%) \\
\text { wh preop anterior sip } \\
\text { increased slip (\%) }\end{array}$ & $\begin{array}{l}23 \\
7 \\
4(57) \\
16 \\
4(25)\end{array}$ & $\begin{array}{l}49 \\
17 \\
13(76) \\
32 \\
10(31)\end{array}$ & $\begin{array}{l}16 \\
5 \\
4(80) \\
11 \\
4(36)\end{array}$ & $\begin{array}{l}4 \\
2 \\
2(100) \\
2 \\
1(50)\end{array}$ \\
\hline
\end{tabular}

\section{DISCUSSION}

\section{Anatomical Basis for Instability}

Adams and Hutton[1] performed laboratory studies in cadavers and found the percentage strength contribution by various structures within the lumbar spine in sagittal translation to be intact facet capsules (39\%), intact disc and ligament (29\%), supraspinous and interspinous ligaments (19\%), and ligamentum flavum (13\%). Cusick, et al.,[7] also demonstrated the importance of the posterior supporting structures. It is not surprising then that performing an extensive lumbar decompression results in a greater likelihood of anterior spondylolisthesis postoperatively. In the current study, $73 \%$ of patients with preoperative anterior spondylolisthesis experienced progressive subluxation following surgery. This compares with $31 \%$ of patients with slippage following surgery who did not have preexisting spondylolisthesis.

The degree of preoperative slippage did not correlate with the likelihood or the degree of postoperative progression. However, as seen in Table 4, the greater the disruption of normal anatomical structures, the greater the likelihood of progressive spondylolisthesis postoperatively. There were no data from our study to suggest that preoperative retrospondylolisthesis or lateral spondylolisthesis significantly contributed to radiologically confirmed progression of spondylolisthesis postoperatively or to a poor clinical outcome.

Results from biomechanical studies would also suggest that preservation of an intact lumbar disc and annular ligament would be important to help prevent spinal instability following surgery. However, our data suggested that disc excision at surgery does not routinely lead to subluxation. In fact, only three of 14 patients in whom discs were removed at surgery in addition to their decompressions experienced 
progressive anterior spondylolisthesis following surgery. In these patients, relatively healthy discs at L-4 and L-5 were removed compared with the relatively degenerated discs in the other 11 patients. This would suggest that the intervertebral disc does become stiffer and more stabilizing as disc height narrows due to degeneration. Hopp and $\mathrm{Tsou}$ [32] found no incidence of progressive subluxation after lumbar decompression associated with discectomy, but this has been disputed by Tuite, et al.[64]

Other anatomical considerations that may lead to a more unstable lumbar spine following decompressive laminectomy include the presence of a minimally degenerated L-4 disc or a markedly narrowed L-3 disc, especially in the presence of minimal anterior column osteophytes.[17,32,34,42,45,60,68] Furthermore, sagittally oriented facet joints at L4-5[23,56] and lateral lumbar curvature[28,58,62] preoperatively were associated with a greater risk for postoperative radiographically confirmed instability.

A minimally degenerated L-4 disc increased the risk for postoperative subluxation. This confirms work reported by Lombardi, et al.,[45] suggesting that preserved disc space heights tended to lead to increased incidence of subluxation following decompressive surgery. Some authors have proposed that a narrowed, degenerative disc is more likely to lead to increased slippage postoperatively,[32,42,52] and this seemed to be true at the L-3 disc level. Severely degenerated and narrowed disc spaces are generally regarded as stabilizing and resist subluxation.[56] We did not find improved outcomes in patients with greater disc space narrowing following surgery as noted by Johnsson and colleagues.[35] Tuite, et al.,[63] suggested that an abnormal disc space angle may be a better radiological marker to predict outcomes than disc space heights.

Sagittally oriented facet joints at L4-5 (mean facet angle $65.8^{\circ}$ ) tended to allow greater slippage following decompression. Additionally, review of preoperative facet joint morphology suggested that patients with slippage following surgery had less coronally oriented facet joint surface ventrally, and this was likely to be removed at the time of medial facetectomy. This confirms works by Robertson, et al.,[56] and Grobler, et al.,[23] all of whom found that assessment of residual facet joint morphology following decompression may be more important in predicting slippage after surgery rather than the absolute amount of joint removed.

\section{Other Factors Influencing Spinal Instability}

A patient's gender may influence the likelihood of postoperative spinal instability.[28,34,56,61,64] Men were found to have a greater incidence of postoperative slippage if they had normal alignment preoperatively (male/female 1.6:1). Conversely, women were more likely to show radiological progression when preexisting spondylolisthesis was present (female/male 1.7:1).

Other factors not found to be associated with increased likelihood of postoperative spinal instability included age,[35,59,68] height, weight, retro- or lateral spondylolisthesis,[32,51] presence of anterior osteophytes,[46] or a low intercrestal line.[15] Relative sagittal angulation measurements were not found to be predictive for postoperative instability. Significant preoperative back pain and difficulty performing activities of daily living also did not correlate well with the development of postoperative spinal instability.[16,49,50]

\section{Radiological Criteria for Spinal Instability}

Controversy has always existed regarding the association of lumbar spondylolisthesis and low-back pain. Equally controversial is whether spondylolisthesis signifies an unstable spine condition and if flexion-extension radiographs truly detect instability. $[9,10,18,53,54,66]$ The absolute determination of 
spinal instability and secondary back pain may be made prior to an operation but they may also develop iatrogenically following an extensive lumbar decompression for stenosis. Therefore, the ability to detect spinal instability can be difficult before, during, and after surgery.

Knutsson[40] originally described degenerative discogenic pain and reported that narrowing of the intervertebral disc space, reactive changes in the adjacent vertebral bodies, vacuum disc phenomenon, spondylolisthesis (anterior or retrograde), and abnormal motion on flexion-extension radiographs of 3 $\mathrm{mm}$ or more were all indicative of lumbar instability. Traction spurs as described by Macnab[47] are also believed to be abnormal and suggest lumbar instability. Posner et al.,[55] and White and Panjabi[67] have developed a radiological checklist for the diagnosis of lumbar instability, but it does not correlate clinical symptoms.[28]

In general, the static presence of anterior spondylolisthesis greater than 3 to $4 \mathrm{~mm}$ or dynamic sagittal plane translation greater than 3 to $4 \mathrm{~mm}$ is suggestive of radiological lumbar instability.[18] It is not known whether retro- and lateral spondylolisthesis have equal connotations, or if the many other radiological signs described previously indicate an unstable spine condition. The presence of these radiological findings in association with a clinically symptomatic patient is the clearest indication of lumbar instability.[9,20,33,63]

An additional test not used in this study but which may prove helpful is lumbar discography. Discography determines the sensitivity of the disc to a mechanical or chemical stimulus and correlates sensitivity with images of internal anatomy to determine if the disc is the source of the patient's clinical pain. Nuclear degeneration likely results in progressive destruction of the nucleus pulposus. If this affects the innervated outer one-third of the disc space, or the annulus, then back and/or extremity pain may develop in the absence of nerve root irritation or radiculopathy.[6,24,48] In patients with spondylolisthesis, traction and additional stresses placed on the subluxated motion segment annular fibers are postulated to be a source of back pain.

If lumbar discography could indeed predict whether a disc was the source of a patient's pain, then fusion would be the gold standard of operation. The main problem, then, is what causes back pain in patients with lumbar stenosis. Generally these patients are older and have significant degenerative changes within both their discs and facet joints. Additionally, deconditioning from leg problems can lead to pain from injuries to the soft tissues of the back. To sort out these causes useful procedures include a careful history and physical examination, flexion-extension radiographs, and magnetic resonance imaging or CT scanning, followed by diagnostic discography or facet injections. Unfortunately, many patients have more than one source for their pain, making this process more difficult to interpret.[13,18,25,27,39,50]

Clinical Criteria for Lumbar Instability. Historically, recurrent, usually acute episodes of low-back pain produced by mechanical stresses of diminishing magnitude suggest clinical instability.[39] The supine position provides more relief than sitting. Patients with associated degenerative central or foraminal lumbar stenosis may also experience pseudoclaudication or leg pain with activity.

Neurological examination is generally normal. Back pain is most likely due to disc degeneration, annular tears, and osteoarthritic changes within the facet joint as proposed by Kirkaldy-Willis and Farfan,[39] as well as others.[28,50] Postoperative low-back pain may persist or result from altered stresses on these same structures or may be due to a wide variety of psychosocial causes.[27] External bracing or immobilization has been used by some authors to determine the potential effects of fusion.[11,18,25]

In our study, 23 of 26 patients with poor outcomes had persistent complaints of low-back pain, which 
could be related to radiological evidence of spinal instability in 11 patients. Other causes likely included degenerative disc disease, painful facet arthropathies, excessive stresses placed on remaining spine-supporting structures following decompression, or other anatomical or physiological factors. Interestingly, Rosenberg[57] noted that back symptoms presumed to be due to instability after decompression diminished with time. His patients generally were able to adapt functionally to their back symptoms, and later fusion was rarely necessary. Katz, et al.,[37] found that patients bothered predominantly by back pain preoperatively were significantly less satisfied with the results of surgery for degenerative lumbar stenosis.

In summary, the more extensive the decompression, the greater the likelihood for progressive spondylolisthesis, with greater than a twofold chance (73\% vs. $31 \%$ ) if spondylolisthesis exists preoperatively. Therefore, it seems intuitive then that the fewer normal anatomical structures violated, the less chance there is for postoperative instability. However, the primary goal for this surgery remains decompression of the neural elements. If destabilization is necessary to achieve this goal, then fusion may be required.

\section{Benefits and Long-Term Complications of Fusions After Decompression for Degenerative Lumbar Spinal Stenosis}

Benefits. Several authors have reported that patients with preoperative spondylolisthesis and stenosis who undergo decompression and fusion experience better outcomes than those in whom a decompression alone is performed.[14,16,30,36,42] Caputy and Luessenhop[4] predicted that $15 \%$ of patients would benefit from concomitant fusions following decompression based on a retrospective analysis of their surgical failures related to progressive radiologically demonstrated subluxation.

Long-Term Complications. The long-term effects on adjacent spinal levels are not well understood, but accelerated degeneration above and below areas of fusion are generally found.[19,41,44] Subsequent acquired spinal stenosis or recurrence of stenosis at previously operated levels could contribute to late failures following lumbar decompressive surgery.[3,4,61] New lumbar instability above or below a previous fusion would also account for late failures. Katz, et al.,[38] reported a 17\% reoperation rate within 4 years for postoperative lumbar instability or stenosis following decompressive surgery. Caputy and Luessenhop[4] predicted that stenosis and spinal instability could affect as many as 50\% of patients within 10 to 15 years postsurgery. In our current study, three (2\%) of our 124 patients developed new symptomatic spinal stenosis at an adjacent unoperated level within 5 years of surgery, whereas no patient developed instability adjacent to a fusion, after an average follow-up period of 5.8 years. Lehmann, et al.,[44] reported that $45 \%$ of patients demonstrated segmental instability at an adjacent level following lumbar fusions without decompressions, after an average 33-year follow up. This was associated with significant stenosis in approximately one-third of cases.

\section{Additional Surgery}

We found seven patients who initially achieved good outcomes but developed recurrent symptoms between 2 and 4 years postoperatively due to progressive subluxation and spinal instability. This suggests that patients may initially adapt to decompression, but repeated stresses on remaining supporting structures and continued degenerative processes can cause destabilization of the spine with resultant pain or neurological symptoms. $[5,38,43]$ Four of these patients underwent fusion procedures, with good or fair outcomes in three. 
Of the 26 patients with poor outcomes after initial surgery, only three had additional surgery. One patient underwent further decompression, and two underwent fusion. All three experienced fair outcomes. Additional surgery was not performed in the remaining 23 patients, and therefore it is unknown whether a fusion procedure would benefit these patients.

\section{CONCLUSIONS}

Based on this retrospective review and a review of the literature, we have drawn the following conclusions.

1) Adequate neural decompression should be the primary goal of surgery for patients with degenerative lumbar stenosis. The extent of bone removal should be dictated by clinical and radiological findings.

2) Radiologically demonstrated instability, as judged by postoperative flexion-extension studies, shows a high incidence of progressive subluxation in all patients after surgery, but is greatest in those with preoperative spondylolisthesis. Notably, however, radiologically demonstrated progression does not necessarily correlate with a poor outcome, particularly in patients with preexisting spondylolisthesis.

3) Radiological factors predictive of progressive anterior subluxation include preoperative anterior spondylolisthesis, abnormal motion on dynamic radiographs, decompression across a minimally degenerated L-4 or markedly degenerated L-3 disc space, CT scans demonstrating sagittally oriented facet joints, or when a radical decompression greater than one level is performed. Patients with these preoperative findings or who are deemed to have an unstable spine following decompression should be considered candidates for fusion.

4) As a group, patients who underwent fusion procedures fared better when compared with those who did not. However, fusion procedures may not necessarily improve outcomes in patients without radiological and/or clinical evidence for spinal instability. Notably, the patients at greatest risk for a poor outcome were those without preoperative spondylolisthesis who did not undergo fusion or develop radiologically confirmed instability postoperatively. In general, all patients with preoperative anterior spondylolisthesis of $5 \mathrm{~mm}$ or more or with movement of $4 \mathrm{~mm}$ or more on flexion-extension radiographs are considered for fusion. These patients must have back pain and be younger than 70 years of age. Prospective, randomized, controlled trials will need to be performed to determine unequivocally the indications for lumbar fusion in patients undergoing decompression for stenosis.

\section{References}

1. Adams MA, Hutton WC: The mechanical function of the lumbar apophyseal joints. Spine 8:327-330, 1983

2. Alexander E Jr, Kelly D Jr, Davis C Jr, et al: Intact arch spondylolisthesis. A review of 50 cases and description of surgical treatment. J Neurosurg 63:840-844, 1985

3. Brodsky AE: Post-laminectomy and post-fusion stenosis of the lumbar spine. Clin Orthop 115:130-139, 1976

4. Caputy AJ, Luessenhop AJ: Long-term evaluation of decompressive surgery for degenerative lumbar stenosis. J Neurosurg 77:669-676, 1992 
5. Chen Q, Baba H, Kamitani K, et al: Postoperative bone re-growth in lumbar spinal stenosis. A multivariate analysis of 48 patients. Spine 19:2144-2149, 1994

6. Colhoun E, McCall IW, Williams L, et al: Provocation discography as a guide to planning operations on the spine. J Bone Joint Surg (Br) 70:267-271, 1988

7. Cusick JF, Yoganandan N, Pintar FA, et al: Biomechanics of sequential posterior lumbar surgical alterations. J Neurosurg 76:805-811, 1992

8. Deen HG Jr, Zimmerman RS, Lyons MK, et al: Analysis of early failures after lumbar decompressive laminectomy for spinal stenosis. Mayo Clin Proc 70:33-36, 1995

9. Dupuis PR, Yong-Hing K, Cassidy JD, et al: Radiologic diagnosis of degenerative lumbar spinal instability. Spine 10:262-276, 1985

10. Dvorak J, Panjabi MM, Novotny JE, et al: Clinical validation of functional flexion-extension roentgenograms of the lumbar spine. Spine 16:943-950, 1991

11. Esses SI, Botsford DJ, Kostuik JP: The role of external spinal skeletal fixation in the assessment of low-back disorders. Spine 14:594-601, 1989

12. Fager CA, Freidberg SR: Analysis of failures and poor results of lumbar spine surgery. Spine 5:87-94, 1980

13. Farfan HF, Gracovetsky S: The nature of instability. Spine 9:714-719, 1984

14. Feffer HL, Wiesel SW, Cuckler JM, et al: Degenerative spondylolisthesis. To fuse or not to fuse. Spine 10:287-289, 1985

15. Fitzgerald JA, Newman PH: Degenerative spondylolisthesis. J Bone Joint Surg (Br) 58:184-192, 1976

16. Fox MW, Onofrio BM, Hanssen AD: Clinical outcomes and radiological instability following decompressive lumbar laminectomy for degenerative spinal stenosis: a comparison of patients undergoing concomitant arthrodesis versus decompression alone. J Neurosurg 85:793-802, 1996

17. Froning EC, Frohman B: Motion of the lumbosacral spine after laminectomy and spine fusion. Correlation of motion with the result. J Bone Joint Surg (Am) 50:897-918, 1968

18. Frymoyer JW: Segmental instability: overview and classification, in Frymoyer JW (ed): The Adult Spine: Principles and Practice. New York: Raven Press, 1991, pp 1873-1891

19. Frymoyer JW, Hanley EN Jr, Howe J, et al: A comparison of radiographic findings in fusion and nonfusion patients ten or more years following lumbar disc surgery. Spine 4:435-440, 1979

20. Frymoyer JW, Newberg A, Pope MH, et al: Spine radiographs in patients with low-back pain. An epidemiological study in men. J Bone Joint Surg (Am) 66:1048-1055, 1984

21. Garfin SR, Herkowitz HN, Mirkovic S, et al: Spinal stenosis: nonoperative and operative treatment, in Rothman RH, Simeone FA (eds): The Spine, ed 4. Philadelphia: WB Saunders, 1992, pp 857-875

22. Gill K, Frymoyer JW: The management of treatment failures after decompressive surgery--surgical 
alternatives and results, in Frymoyer JW (ed): The Adult Spine: Principles and Practice. New York: Raven Press, 1991, pp 1849-1870

23. Grobler LJ, Robertson PA, Novotny JE, et al: Decompression for degenerative spondylolisthesis and spinal stenosis at L4-5. The effects on facet joint morphology. Spine 18:1475-1482, 1993

24. Guyer RD, Ohnmeiss DD: Lumbar discography. Position statement from the North American Spine Society Diagnostic and Therapeutic Committee. Spine 20:2048-2059, 1995

25. Haid RW Jr, Dickman CA: Instrumentation and fusion for discogenic disease of the lumbosacral spine. Neurosurg Clin North Am 4:135-148, 1993

26. Hall S, Bartleson JD, Onofrio BM, et al: Lumbar spinal stenosis. Clinical features, diagnostic procedures, and results of surgical treatment in 68 patients. Ann Intern Med 103:271-275, 1985

27. Hanley EN Jr, Phillips ED, Kostuik JP: Who should be fused?, in Frymoyer JW (ed): The Adult Spine: Principles and Practice. New York: Raven Press, 1991, pp 1893-1917

28. Herkowitz HN, el-Kommos H: Spinal stenosis: clinical evaluation and differential diagnosis, in Rothman RH, Simeone FA (eds): The Spine. Philadelphia: WB Saunders, 1993, pp 827-857

29. Herkowitz HN, Garfin SR: Decompressive surgery for spinal stenosis. Semin Spine Surg 1:163-167, 1989

30. Herkowitz HN, Kurz LT: Degenerative lumbar spondylolisthesis with spinal stenosis. A prospective study comparing decompression with decompression and intertransverse process arthrodesis. J Bone Joint Surg (Am) 73:802-808, 1991

31. Herron LD, Trippi AC: L4-5 degenerative spondylolisthesis. The results of treatment by decompressive laminectomy without fusion. Spine 14:534-538, 1989

32. Hopp E, Tsou PM: Postdecompression lumbar instability. Clin Orthop 227:143-151, 1988

33. Iida Y, Kataoka O, Sho T, et al: Postoperative lumbar spinal instability occurring or progressing secondary to laminectomy. Spine 15:1186-1189, 1990

34. Johnsson K, Redlund-Johnell I, Uden A, et al: Preoperative and postoperative instability in lumbar spinal stenosis. Spine 14:591-593, 1989

35. Johnsson KE, Willner S, Johnsson K: Postoperative instability after decompression for lumbar spinal stenosis. Spine 11:107-110, 1986

36. Kaneda K, Kazama H, Satoh S, et al: Follow-up study of medial facetectomies and posterolateral fusion with instrumentation in unstable degenerative spondylolisthesis. Clin Orthop 203:159-167, 1986

37. Katz JN, Lipson SJ, Brick GW, et al: Clinical correlates of patient satisfaction after laminectomy for degenerative lumbar spinal stenosis. Spine 20:1155-1160, 1995

38. Katz JN, Lipson SJ, Larson MG, et al: The outcome of decompressive laminectomy for degenerative lumbar stenosis. J Bone Joint Surg (Am) 73:809-816, 1991

39. Kirkaldy-Willis WH, Farfan HF: Instability of the lumbar spine. Clin Orthop 165:110-123, 1982 
40. Knutsson F: The instability associated with disk degeneration in the lumbar spine. Acta Radiol 25:593-609, 1944

41. Lee CK: Accelerated degeneration of the segment adjacent to a lumbar fusion. Spine 13:375-377, 1988

42. Lee CK: Lumbar spinal instability (olisthesis) after extensive posterior spinal decompression. Spine 8:429-433, 1983

43. Lee CK, Langrana NA: Lumbosacral spinal fusion. A biomechanical study. Spine 9:574-581, 1984

44. Lehmann TR, Spratt KF, Tozzi JE, et al: Long-term follow-up of lower lumbar fusion patients. Spine 12:97-104, 1987

45. Lombardi JS, Wiltse LL, Reynolds J, et al: Treatment of degenerative spondylolisthesis. Spine 10:821-827, 1985

46. Macnab I: Spondylolisthesis with an intact neural arch-the so-called pseudo-spondylolisthesis. J Bone Joint Surg (Br) 32:325-333, 1950

47. Macnab I: The traction spur. An indicator of segmental instability. J Bone Joint Surg (Am) 53:663-670, 1971

48. Moneta GB, Videman T, Kaivanto K, et al: Reported pain during lumbar discography as a function of annular ruptures and disc degeneration. A re-analysis of 830 discograms. Spine 19:1968-1974, 1994

49. Mooney V, Robertson J: The facet syndrome. Clin Orthop 115:149-156, 1976

50. Morgan FP, King T: Primary instability of lumbar vertebrae as a common cause of low back pain. J Bone Joint Surg (Br) 39:6-22, 1957

51. Nakai O, Ookawa A, Yamaura I: Long-term roentgenographic and functional changes in patients who were treated with wide fenestration for central lumbar stenosis. J Bone Joint Surg (Am)

73:1184-1191, 1991

52. Nasca RJ: Rationale for spinal fusion in lumbar spinal stenosis. Spine 14:451-454, 1989

53. Pearcy M, Shepherd J: Is there instability in spondylolisthesis? Spine 10:175-177, 1985

54. Penning L, Blickman JR: Instability in lumbar spondylolisthesis: a radiologic study of several concepts. AJR 134:293-301, 1980

55. Posner I, White AA III, Edwards WT, et al: A biomechanical analysis of the clinical stability of the lumbar and lumbosacral spine. Spine 7:374-389, 1982

56. Robertson PA, Grobler LJ, Novotny JE, et al: Postoperative spondylolisthesis at L4-5. The role of facet joint morphology. Spine 18:1483-1490, 1993

57. Rosenberg NJ: Degenerative spondylolisthesis: surgical treatment. Clin Orthop 117:112-120, 1976

58. San Martino A, D'Andria FM, San Martino C: The surgical treatment of nerve root compression caused by scoliosis of the lumbar spine. Spine 8:261-265, 1983 
59. Shenkin HA, Hash CJ: Spondylolisthesis after multiple bilateral laminectomies and facetectomies for lumbar spondylosis. Follow-up review. J Neurosurg 50:45-47, 1979

60. Sienkiewicz PJ, Flatley TJ: Postoperative spondylolisthesis. Clin Orthop 221:172-180, 1987

61. Silvers HR, Lewis PJ, Asch HL: Decompressive lumbar laminectomy for spinal stenosis. J Neurosurg 78:695-701, 1993

62. Simmons ED Jr, Simmons EH: Spinal stenosis with scoliosis. Spine 17 (Suppl):S117-S120, 1992

63. Tuite GF, Doran SE, Stern JD, et al: Outcome after laminectomy for lumbar spinal stenosis. Part II: Radiographic changes and clinical correlations. J Neurosurg 81:707-715, 1994

64. Tuite GF, Stern JD, Doran SE, et al: Outcome after laminectomy for lumbar spinal stenosis. Part I: Clinical correlations. J Neurosurg 81:699-706, 1994

65. Turner JA, Ersek M, Herron L, et al: Patient outcomes after lumbar spinal fusions. JAMA 268:907-911, 1992

66. Weinstein JM, Rydevik BL: The pain of spondylolisthesis. Semin Spine Surg 1:100-105, 1989

67. White AA III, Panjabi MM: Clinical Biomechanics of the Spine, ed 2. Philadelphia: JB Lippincott, 1990, pp 342-378

68. White AH, Wiltse LL: Postoperative spondylolisthesis, in Weinstein PR, Ehni G, Wilson CB (eds): Lumbar Spondylosis: Diagnosis, Management, and Surgical Treatment. Chicago: Yearbook Medical, 1977, pp 184-194

69. Zdeblick TA: A prospective, randomized study of lumbar fusion. Preliminary results. Spine 18:983-991, 1993

Manuscript received June 2, 1997.

Accepted in final form July 15, 1997.

Address reprint requests to: Burton M. Onofrio, M.D., Department of Neurosurgery, The Mayo Clinic, 200 First Avenue SW, Rochester, Minnesota 55905. 